\title{
Observational evidence of moistening the lowermost stratosphere via isentropic mixing across the subtropical jet
}

\author{
Jeffery Langille ${ }^{1}$, Adam Bourassa ${ }^{1}$, Laura L. Pan ${ }^{2}$, Daniel Letros ${ }^{1}$, Brian Solheim ${ }^{1}$, Daniel Zawada ${ }^{1}$, and \\ Doug Degenstein ${ }^{1}$ \\ ${ }^{1}$ Institute of Space and Atmospheric Studies, University of Saskatchewan, Saskatoon, S7N 5E2, Canada \\ ${ }^{2}$ National Center for Atmospheric Research, Boulder, CO 80301, USA \\ Correspondence: Jeffery Langille (jeff.langille@ usask.ca)
}

Received: 10 October 2019 - Discussion started: 15 November 2019

Revised: 7 April 2020 - Accepted: 9 April 2020 - Published: 12 May 2020

\begin{abstract}
Isentropic mixing across and above the subtropical jet is a significant mechanism for stratosphere-troposphere exchange. In this work, we show new observational evidence on the role of this process in moistening the lowermost stratosphere. The new measurement, obtained from the Spatial Heterodyne Observations of Water (SHOW) instrument during a demonstration flight on the NASA's ER-2 high-altitude research aircraft, captured an event of poleward water vapour transport, including a fine-scale (vertically $<\sim$ $1 \mathrm{~km})$ moist filament above the local tropopause in a highspatial-resolution two-dimensional cross section of the water vapour distribution. Analysis of these measurements combined with ERA5 reanalysis data reveals that this poleward mixing of air with enhanced water vapour occurred in the region of a double tropopause following a large Rossby wavebreaking event. These new observations highlight the importance of high-resolution measurements in resolving processes that are important to the lowermost-stratosphere water vapour budget.
\end{abstract}

\section{Introduction}

The distribution of water vapour in the upper troposphere and lower stratosphere (UTLS) plays a critical role in the physical processes that couple the region to Earth's climate. This is especially true near the tropopause and in the lower stratosphere, where the radiative sensitivity and climate impact of water vapour is most significant (de Forster and Shine, 1999, 2002; Solomon et al., 2010). Several studies have shown that trends in stratospheric water vapour affect long-term and re- cent climate trends (e.g., Solomon et al., 2010; Dessler et al., 2013; Banerjee et al., 2019). Due to the strong gradient in the water vapour distribution across the tropopause and the fact that controlling mechanisms often involve small-scale processes, quantifying stratospheric water vapour and its trends remains challenging for both observations and modelling (Kley et al., 2000; Gettelman et al., 2010; Riese et al., 2012; Nedoluha et al., 2017; Khosrawi, et al., 2018).

In this work, we present a case study of high-spatialresolution observations of UTLS water vapour that has been enabled by new measurement technology. The measurements, using the Spatial Heterodyne Observations of Water (SHOW) instrument (Langille et al., 2019) aboard the NASA ER-2 research aircraft during a demonstration flight, captured an event of water vapour transport into the lowermost stratosphere across the subtropical jet. Using the ECMWF ERA5 reanalysis product, we demonstrate that the transport is driven by a large-scale Rossby wave-breaking event and in association with the occurrence of a double tropopause. Together, the result demonstrates the importance of isentropic transport processes for the stratospheric water vapour budget and the importance of high-resolution water vapour measurements in the UTLS.

In the middle world, the layer of atmosphere between 310 and $380-400 \mathrm{~K}$, the isentropic surfaces intersect the tropopause in the subtropics (Holton, 1995, and reference therein). A ubiquitous feature here is a sudden decrease in the altitude of the thermal tropopause near the subtropical jet, known as the "tropopause break". The layer poleward of the break is defined as the lowermost stratosphere and is strongly influenced by transport via isentropic mixing associ- 
ated with Rossby wave breaking (e.g., Chen, 1995; Scott and Cammas, 2002). The role of isentropic mixing in the budget of lowermost-stratosphere water vapour has been highlighted by both in situ airborne and balloon observations (e.g., Dessler et al., 1995; Hintsa et al., 1998; Ray et al., 1999) and satellite measurements (e.g., Pan et al., 1997). A number of more recent studies have shown that the occurrence of a double tropopause can be associated with Rossby wave breaking and large-scale poleward transport. Chemical signatures of this type of transport have been observed in ozone and a number of other species (Pan et al., 2009; Homeyer et al., 2011; Ungermann et al., 2013). The observation reported in this work, however, represents the first such measurement of the two-dimensional structure of the water vapour distribution.

The SHOW instrument is a new limb-sounding satellite prototype originally designed and built at York University that is being further developed in collaboration between the University of Saskatchewan and the Canadian Space Agency to provide high-vertical-resolution $(<250 \mathrm{~m})$ measurements of water vapour with high precision $(< \pm 1 \mathrm{ppm})$ in the UTLS region. The prototype version of the instrument (see Sect. 2) made several demonstration flights on NASA's ER-2 airplane in July 2017 in order to validate the measurement approach and to demonstrate the along-track sampling capabilities of the instrument. The measurement technique, retrieval approach, and instrument performance were validated during an engineering flight that was performed on 17 July 2017 (Langille et al., 2019). Co-located radiosonde measurements were found to be in excellent agreement, with the radiosonde recording a positive bias of $\sim 3.3 \%$ relative to SHOW and percent differences of $< \pm 10 \%$, due to both natural variability between the observations and measurement precision.

The analysis of this work focuses on another flight performed on 21 July 2017. The flight path (Fig. 1), across several degrees of latitude off the western coast of North America, from roughly 34 to $48^{\circ} \mathrm{N}$ along the $124.5^{\circ} \mathrm{W}$ longitude line, was chosen in an attempt to observe potential mixing near the tropopause break in a region known to have a relatively frequent occurrence of double tropopauses in the summer season (Añel et al., 2008). This mixing process often produces fine-scale filaments that are difficult for the satellite measurements and the large-scale models to resolve. The result of the measurement indeed shows fine-scale water vapour structures, which reveals poleward mixing of moist filaments in the region of a double tropopause, demonstrating the capability of the new measurement technology in capturing the climate-relevant water vapour transport process.

Meteorological fields determined from the ECMWF ERA5 reanalysis are used to examine the dynamical setting of the measurements. To support the process understanding, the Rossby wave-breaking event that proceeds the observation is examined using isentropic maps of potential vorticity (PV). Also examined to support the process identification are the nearly coincident retrievals of ozone and water vapour from the Microwave Limb Sounder aboard the AURA satellite (AURA-MLS).

\section{The Spatial Heterodyne Observations of Water (SHOW) instrument}

The SHOW instrument is a spatial heterodyne spectrometer (SHS) that has been optimized for limb-viewing observations of limb-scattered sunlight within a vibrational band of water. The limb is imaged conjugate to the SHS interference fringes such that each interferogram row and subsequently each spectral row in the image are mapped 1-to-1 to the line of sight at the limb. Each sample provides a vertically resolved spectral image with $\sim 0.03 \mathrm{~nm}$ spectral resolution in a $3 \mathrm{~nm}$ window centered on $1364.5 \mathrm{~nm}$. These vertically resolved spectral images are inverted using a non-linear optimal estimation approach to obtain the vertical distribution of water vapour. The SHOW measurement technique and retrieval algorithm are discussed in previous publications (Langille et al., 2017, 2018, 2019).

The prototype SHOW instrument is optimized for observations from NASA's ER-2 airplane and is mounted in a forward-looking wing pod to observe a $4^{\circ} \times 5.1^{\circ}$ (vertical $\times$ horizontal) field of view. Flying at an altitude of $21 \mathrm{~km}$, the viewing geometry and optical configuration provide a vertical sampling at the limb tangent point of 51 to $171 \mathrm{~m}$, increasing towards the ground tangent. The instrument utilizes anamorphic optics to average over the scene in the horizontal dimension; therefore, no horizontal (longitudinal) scene information is obtained. Using this configuration, retrievals are performed on a $250 \mathrm{~m}$ retrieval grid with no smoothing to provide an approximate vertical resolution of $250 \mathrm{~m}$ from $13 \mathrm{~km}$ up to $18 \mathrm{~km}$ with precisions better than $1 \mathrm{ppm}$. The instrument can be operated using sampling rates from the $0.1 \mathrm{~Hz}$ up to the $2 \mathrm{~Hz}$ mode; however, the measurements discussed in this paper are obtained using a sampling rate of $1 \mathrm{~Hz}$. This provides an approximate raw along-track sampling of $\sim 0.5 \mathrm{~km}$ at the surface. The primary instrument specifications are listed in Table 1, and the full instrument configuration is presented in Langille et al. (2019).

\section{ER-2 flight track and the metrological background}

The measurements discussed in this paper were obtained during a flight aboard the ER-2 performed on 21 July 2017 between 18:00 and 19:00 UTC off the western coast of North America. For analysis of the meteorological fields within this measurement window, we utilize the ECMWF (ERA5) reanalysis products, which are provided in $1 \mathrm{~h}$ time steps on a $0.25^{\circ} \times 0.25^{\circ}$ grid (latitude $\times$ longitude) at 37 pressure levels from $1 \mathrm{hPa}$ up to $1000 \mathrm{hPa}$.

To provide the dynamical background of the flight track, the zonal wind at the $175 \mathrm{hPa}$ level (approximately $13 \mathrm{~km}$ altitude) for the 18:00:00 UTC time step on 21 July 2017 is 
Table 1. SHOW ER-2 instrument parameters.

\begin{tabular}{ll}
\hline Instrument parameter & Specification \\
\hline ER-2 airplane altitude & $\sim 21.34 \mathrm{~km}(70000 \mathrm{ft}$ maximum) \\
Airplane speed & $\sim 760 \mathrm{~km} \mathrm{~h}^{-1}$ (maximum at altitude) \\
Field of view & $4^{\circ}$ vertical by $5.1^{\circ}$ horizontal \\
Temporal cadence & $1 \mathrm{~Hz}$ or $0.5 \mathrm{~Hz}$ \\
Spatial sampling at the surface & $\sim 0.5 \mathrm{~km}$ at $1 \mathrm{~Hz}$ \\
Instantaneous angular vertical resolution & $0.0176^{\circ}$ \\
Retrieval altitudes & 13 to $18 \mathrm{~km}$ \\
Retrieval grid & $250 \mathrm{~m}$ \\
Mass & $222.68 \mathrm{lbs}(101 \mathrm{~kg})$ \\
Power & $465 \mathrm{~W}(\mathrm{peak}), 200 \mathrm{~W}$ (average) \\
Dimensions & $(0.465 \mathrm{~m} \times 1.32 \mathrm{~m} \times 0.38 \mathrm{~m})$ \\
Spectral resolution (unapodized) & $\sim 0.03 \mathrm{~nm}$ \\
Spectral range & $1363-1366 \mathrm{~nm}$ \\
\hline
\end{tabular}

shown in Fig. 1. The zonal wind field shows a double-jet structure, with the subtropical jet located near $35^{\circ} \mathrm{N}$ and the polar jet near $45^{\circ} \mathrm{N}$. Both features have jet cores (with winds $>40 \mathrm{~m} \mathrm{~s}^{-1}$ ) that are located over the Pacific Ocean. As the subtropical jet shifts north, downstream in an anticyclonic flow, the two jets merge over North America. This configuration is formed with a large-scale Rossby wave-breaking event that developed over several days prior to the SHOW measurements and is demonstrated in Fig. 2 using the $380 \mathrm{~K}$ isentropic potential vorticity in $48 \mathrm{~h}$ intervals over a $6 \mathrm{~d}$ period. To further connect with the ER-2 track, the potential vorticity on the 380 and $400 \mathrm{~K}$ surfaces is shown in Fig. 3 for the 21 July 2017 time step. Here, we used 6 PVU to identify the separation between tropospheric air on the $380 \mathrm{~K}$ surface (Kunz et al., 2011a, b), which is noted by the white transition region between red (low-PV air and tropospheric) and blue (high-PV air and stratospheric) colours in the figure. A welldefined low-PV structure consistent with tropospheric air is observed on the $380 \mathrm{~K}$ surface that extends from the western Pacific up to the extratropical region over North America as a result of the wave breaking. Similarly, we used 8 PVU to represent this separation on the $400 \mathrm{~K}$ isentropic surface, which consistently highlighted the filament of tropical air (more tropospheric) in the background of extratropical (lower stratospheric) background.

To characterize the dynamical structure vertically, the height of the thermal tropopause and the occurrence of the double tropopause are shown in Fig. 4. Here the tropopause is derived using the ERA5 temperature field using the lapse rate definition (WMO, 1957, 1992) with a modification. The modified version locates the first tropopause as the lowest level where the lapse rate drops below $2 \mathrm{~K} \mathrm{~km}^{-1}$ and remains below that value on average for $1 \mathrm{~km}$ (instead of $2 \mathrm{~km}$ ). A second tropopause is identified if the lapse rate increases above $2 \mathrm{~K} \mathrm{~km}^{-1}$ (instead of $3 \mathrm{~K} \mathrm{~km}^{-1}$ ) and then decreases again below $2 \mathrm{~K} \mathrm{~km}^{-1}$. This is done to remedy the coarse vertical resolution of the of the temperature data. This type
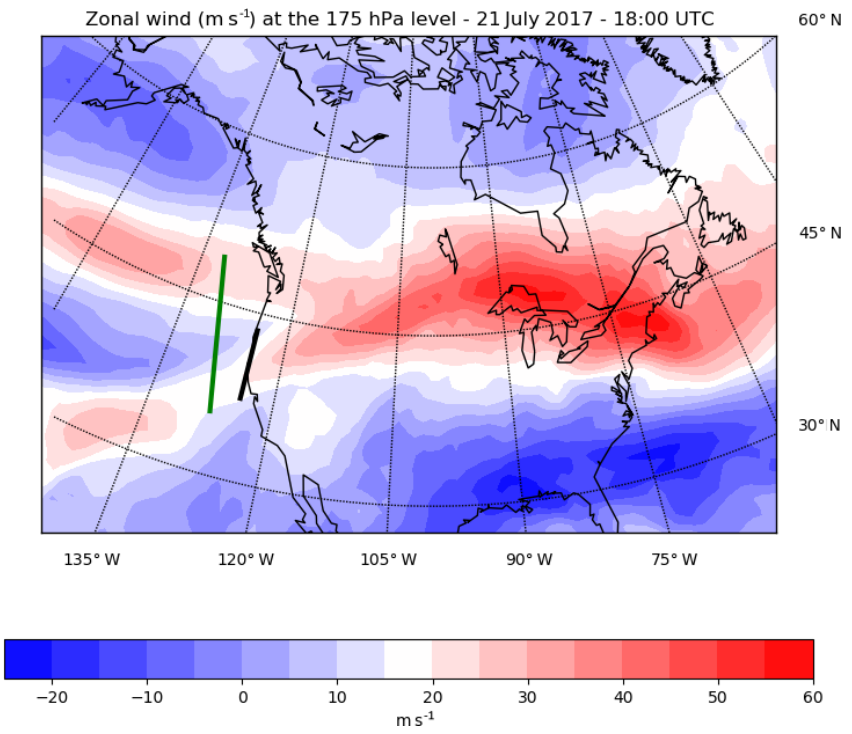

Figure 1. Zonal wind on the $175 \mathrm{hPa}$ surface for the 18:00 UTC, 21 July 2017, time step. The ER-2 flight track with the SHOW measurements is shown as the black line, and the closest measurement track of the AURA-MLS instrument is shown as the dark green line.

of modification has been recognized to allow identification of the double tropopause derived from coarse-resolution temperature data that are more consistent with high-resolution observational data (Randel et al., 2007). Our goal here is to highlight the spatial extent of the layered static stability structure as discussed in Sects. 4-5. The height distribution of the primary tropopause is shown in Fig. 4a. The distribution of the secondary tropopause, shown in Fig. 4b, is consistent with the formation mechanism of a poleward wave breaking along the subtropical jet (Pan et al., 2009). Although not shown here, the double-tropopause features have varying strength from time step to time step on the days leading up to and after the flight. Occurrences of dou- 
(a) $07 / 15 / 2017$ 20:00 UTC

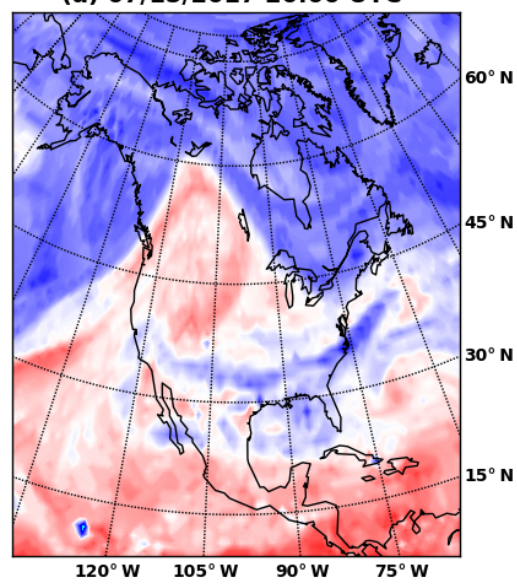

(b) $07 / 17 / 201720: 00$ UTC

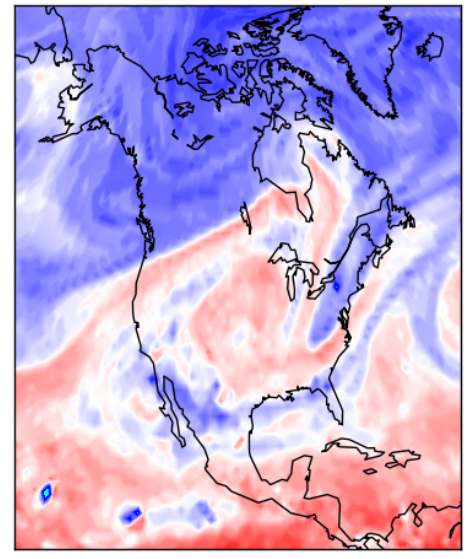

(c) $07 / 19 / 201720: 00$ UTC

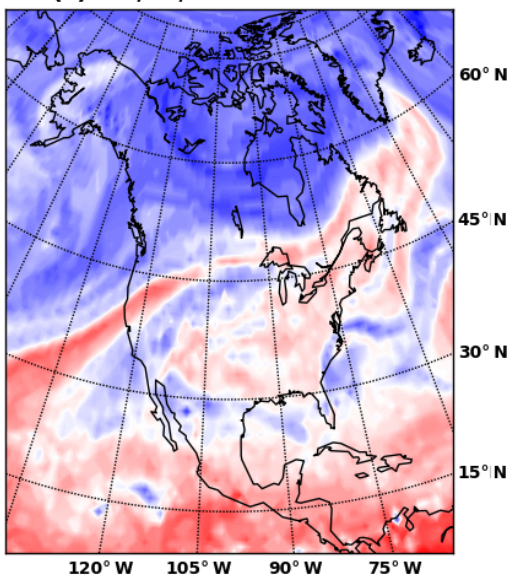

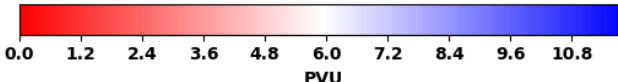

Figure 2. Potential vorticity on the $380 \mathrm{~K}$ isentropic surface on 15, 17, and 19 July 2017 at 20:00 UTC, showing a Rossby wave-breaking event several days prior to the SHOW measurements.

ble tropopauses are common in this region, with the highest occurrence rate in the winter (Swartz et al., 2015); however, they are also observed in the summer season (Añel et al., 2008).

The ER-2 flight track with the SHOW instrument for the 18:00 to 19:00 UTC time period, as indicated in Figs. 1, 3, and 4 , includes the edge of a large double-tropopause region that extends off the West Coast of the United States. For process verification using an independent measurement, we identified a near co-located MLS satellite observation track, also marked in Figs. 1, 3, and 4. Analyses of the SHOW and MLS measurements are discussed in Sects. 4 and 5 respectively.

\section{SHOW observations}

We begin the analysis of SHOW water vapour measurements with three example profiles, shown in Fig. 5a-c, which correspond to the latitude bins centered at 37.4, 41.87, and $43.48^{\circ} \mathrm{N}$ respectively. Each example shows the set of 10 samples obtained within each latitude bin (black) and the mean of the sample set (red). The observed variance in the water vapour distribution closely matches the 1-2 ppm measurement error predicted by propagating the noise through the retrieval. The red error bars show the precision for the averaged measurements, which is less than $<0.3 \mathrm{ppm}$ for most measurement altitudes. The upper and lower boundaries of the retrievals presented in this paper are $18 \mathrm{~km}$ and $13.5 \mathrm{~km}$ respectively. The altitude of the first and second lapse rate
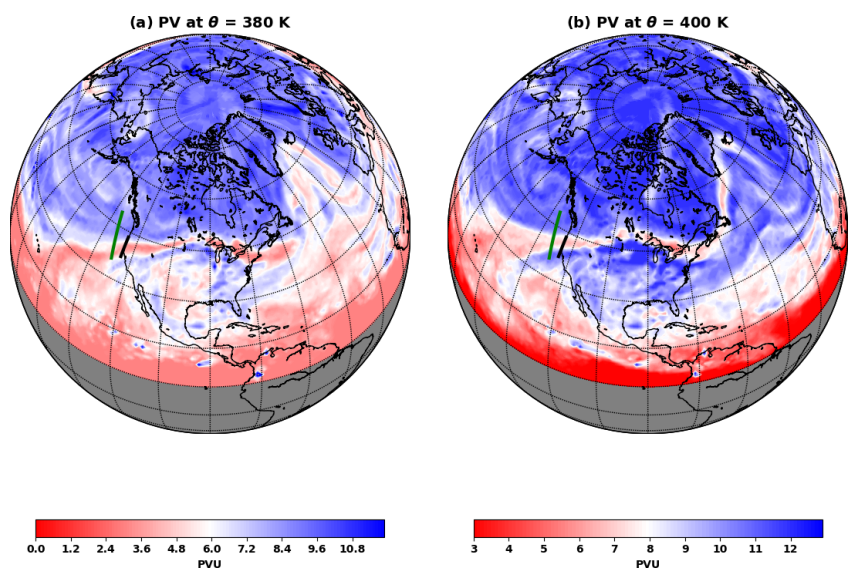

Figure 3. Potential vorticity on the 380 (a) and $400 \mathrm{~K}$ (b) isentropic surfaces for the 18:00 UTC, 21 July 2017, time step. The measurement tracks of SHOW and MLS are shown in black and green respectively.

tropopause are shown as blue solid and dashed lines respectively.

For the $37.4^{\circ} \mathrm{N}$ measurement, the water vapour mixing ratio increases to a maximum near $14.5 \mathrm{~km}$ and then decreases rapidly with increasing altitude. The water vapour mixing ratio is also found to decrease slightly below $14.6 \mathrm{~km}$. In the current analysis, the lower boundary of the retrieval is at $13.5 \mathrm{~km}$ and therefore does not capture the expected increase of water vapour at altitudes below $13.5 \mathrm{~km}$. At $41.87^{\circ} \mathrm{N}$ a secondary peak in the water vapour profile is observed near $16.5 \mathrm{~km}$. The amount of water vapour decreases slightly be- 

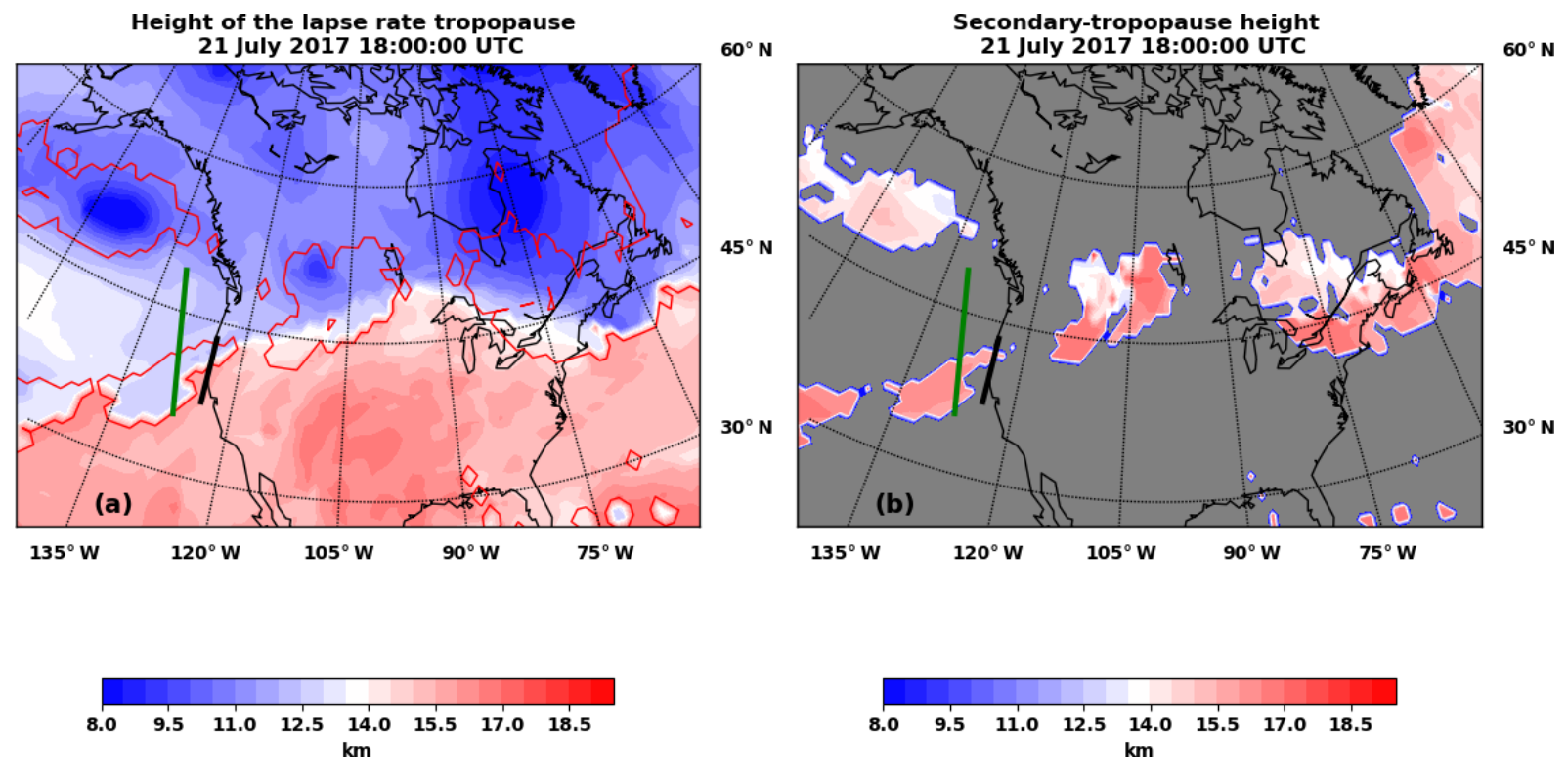

Figure 4. Height of the thermal tropopause (a) and the height of the secondary tropopause (b) for the 18:00 UTC time step. The red outline in (a) denotes the edge of the double-tropopause regions shown in (b). The measurement tracks of SHOW and MLS are shown in black and green respectively.
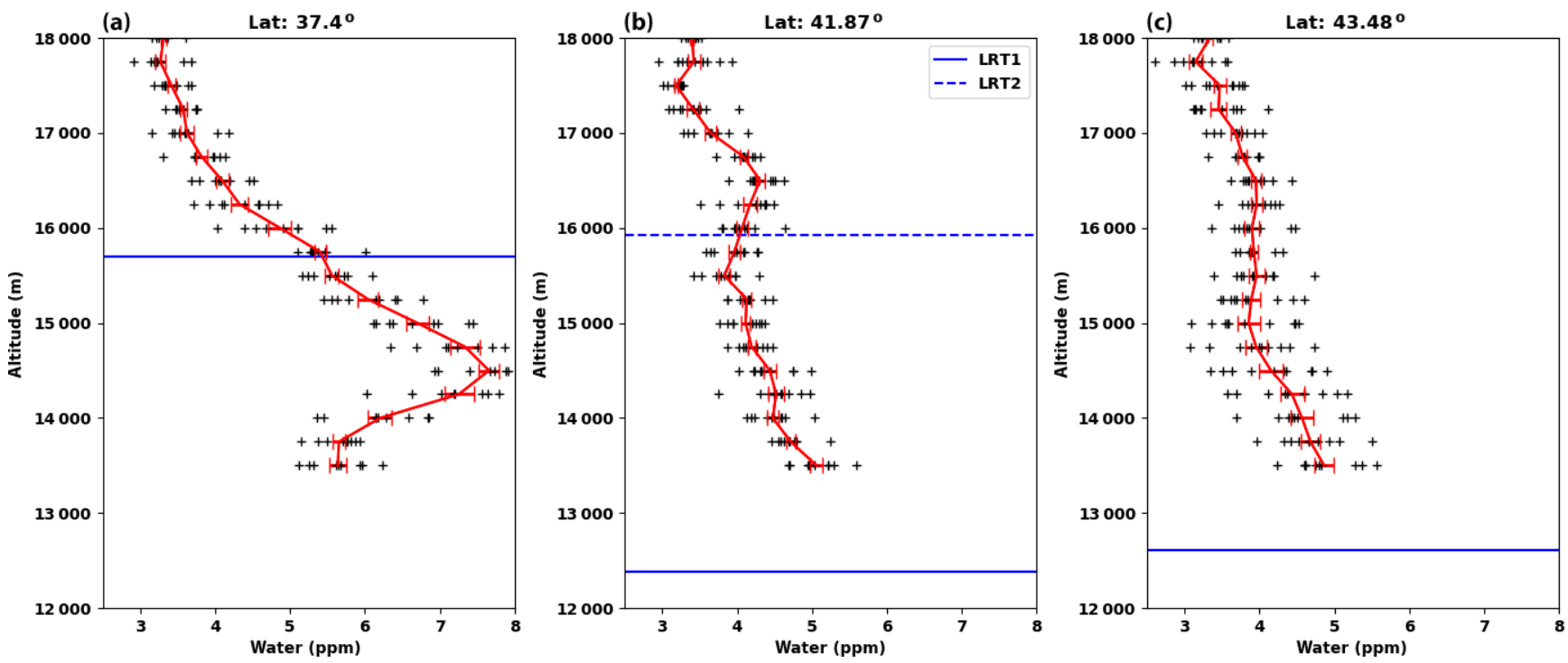

Figure 5. Example SHOW profiles at 37.4 (a), $41.87^{\circ} \mathrm{N}$ (b), and 43.48 (c). All profiles lie closely along the $124.5^{\circ} \mathrm{W}$ longitude line. The black data points correspond to each of the individual profiles, and the red line is the average of all latitude measurements in each altitude bin. The error bars show the precision of the averaged measurements. The first and second tropopause are identified as the solid blue and dotted blue lines respectively.

low this peak and then continues to steadily increase with decreasing altitude. Further along the flight track, at $43.48^{\circ} \mathrm{N}$, the peak at $16.5 \mathrm{~km}$ diminishes and the amount of water vapour increases slowly with decreasing altitude.

All of the measured water vapour profiles obtained along the flight track are stacked and plotted as a single data curtain in Fig. 6a. Along this track, SHOW obtained highvertical-resolution $(<250 \mathrm{~m})$ measurements of UTLS wa- ter vapour around the tropopause $(13-18 \mathrm{~km})$. These measurements were then averaged by latitude to increase the signal-to-noise ratio, resulting in an along-track sampling of approximately $0.32^{\circ}$ latitude. The result provides a highvertical-resolution time-height (latitude-height) cross section of the water vapour distribution along the flight track. The dynamical fields, including zonal wind, potential vorticity, and the derived tropopause locations from the ECMWF 


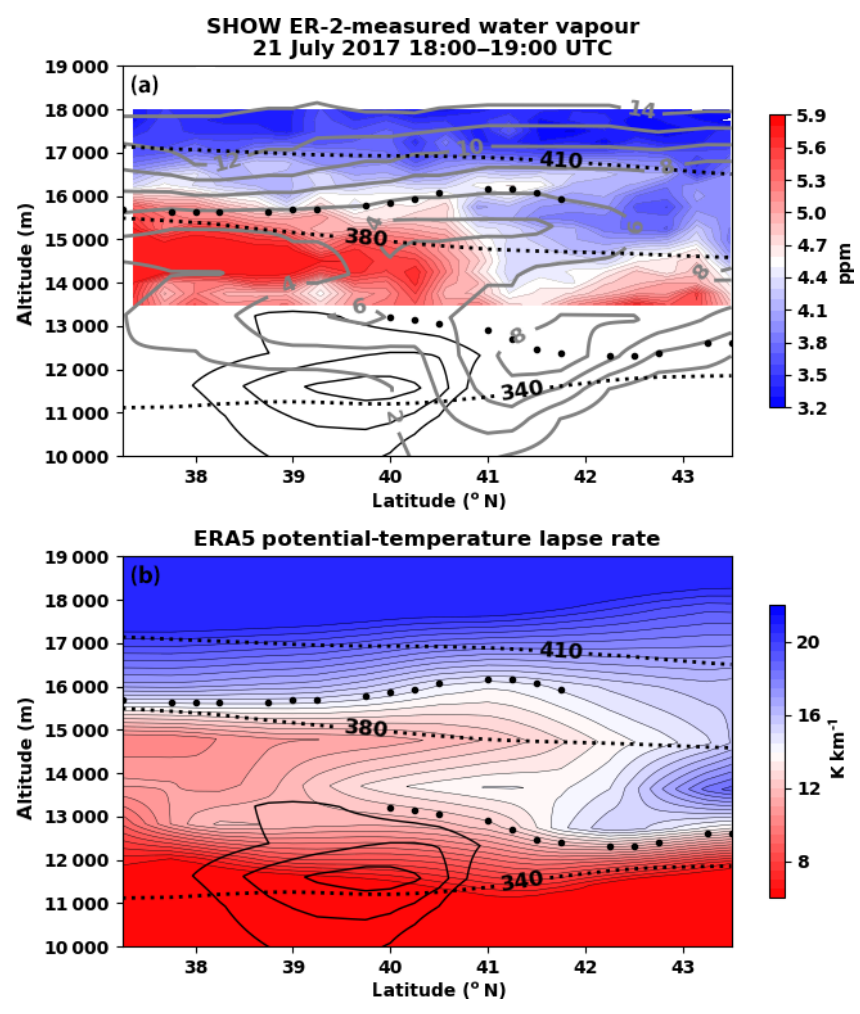

Figure 6. SHOW-measured water vapour profile (from 18:00 to 19:00 UTC) (a) and the potential-temperature lapse rate determined from the ERA5 reanalysis for the 19:00 UTC time step along the SHOW measurement track (b). The dark dotted line shows the location of the thermal tropopause. The grey contours show the potential vorticity; several zonal wind contours are shown in black; and the light black dotted line shows the 340,380 , and $410 \mathrm{~K}$ isentropes respectively. The longitude is along the $124.5^{\circ} \mathrm{W}$ line and is nearly constant for the measurements.

ERA5 reanalysis (19:00 UTC time step), are overlaid on top of the water vapour measurements. The dynamical structure in the cross section co-located with the flight track is further examined in Fig. $6 \mathrm{~b}$, where the structure of the static stability is highlighted using the potential-temperature lapse rate (PTLR) determined from the reanalysis data (PTLR $=$ $\Delta \theta / \Delta z$ ). In both panels, the 340,380 , and $410 \mathrm{~K}$ isentropes are shown as the thin dotted lines, and the thick black dots identify the location of the thermal tropopause.

The $410 \mathrm{~K}$ isentrope lies entirely in the stratosphere (in the overworld) at all latitudes. Above the $410 \mathrm{~K}$ isentrope, the water vapour mixing ratio is observed to have values between 3.0 and $4.0 \mathrm{ppm}$, which defines the background water vapour mixing ratio in the lowermost stratosphere. Near the tropopause (in the middle world), sharp spatial structures are resolved that have gradients on the order of $0.5 \mathrm{ppm}$ per $250 \mathrm{~m}$ sampling bin. SHOW does not record the water vapour distribution below the $340 \mathrm{~K}$ isentrope, since the retrieval cuts off at an altitude of $13.5 \mathrm{~km}$. Discussion of this lower boundary is presented in Sect. 6 .
The dynamical structure of the cross section identifies the flight track extended over a well-defined tropopause break over the jet core, which is indicated by tight zonal wind contours (black) near $39.9^{\circ} \mathrm{N}$. South of $39.9^{\circ} \mathrm{N}$, the thermal tropopause is located at an altitude of close to $15.5 \mathrm{~km}$. The region of 39.9 to $42^{\circ} \mathrm{N}$ has a double-tropopause structure. More importantly, the region of the tropopause break has a layered structure of static stability, showing a layer of low-stability, troposphere-like air mass extending poleward over the primary tropopause. Consistent with the stability structure, the PV field (grey) in the region shows a weakened gradient. Overall, the dynamical background has a large similarity with the observed tropospheric intrusion from the HIRDLS satellite ozone case study (Fig. 1 in Pan et al., 2009).

Water vapour measurements from SHOW (Fig. 6a) recorded a layer with a water vapour mixing ratio greater than 5 ppmv, which is much higher than the stratospheric background, centered at roughly $14.6 \mathrm{~km}$, and extends poleward to about $40.5^{\circ} \mathrm{N}$ above the local primary tropopause. Note that the layer in between the two tropopauses where the PV distribution shows a weakened gradient between the 4 and 8 PVU contours indicates a weakened tropopause (Pan et al., 2009; Kunz et al., 2011a, b). Further poleward, the SHOW measurements captured part of a layer with enhanced water vapour above the primary tropopause between 41.5 and $43.5^{\circ} \mathrm{N}$. The moist layer is also co-located with the weakened PV gradient.

While the static stability structure of the cross section (Fig. 6b) indicates a case of intrusion of low-static-stability air from the subtropical troposphere into the mid-latitude lowermost stratosphere, the quasi-isentropic transport indicated by the SHOW water vapour cross section does not entirely match the stability structure. Considering that the observation is made in the advent of the Rossby wave-breaking event, it is physically reasonable that the dynamical field and chemical structure are no longer intact, which is a sign of irreversible transport. It is also likely due to the ERA5 products available to the analysis that are given in much coarser vertical resolution compared to the SHOW measurements. The important point is that there is a clear process identification supported by both the water vapour measurement and the dynamical field analysis. We see a similar shift in the analysis of the MLS water vapour and ozone data in the following section.

\section{AURA-MLS ozone and water vapour}

For additional process verification, we examine measurements of water vapour and ozone that were obtained along a nearly coincident measurement track as shown in Fig. 1 (solid green line). The AURA-MLS satellite instrument obtained measurements along this track at approximately 21:50 UTC - roughly $2 \mathrm{~h}$ after the SHOW measurements 
were performed. Along this track, the MLS instrument sampled the same geophysical feature along a slightly different path with a horizontal resolution of $168-230 \mathrm{~km}$ and a vertical resolution of $1.3-3.2 \mathrm{~km}$ in the UTLS (316-46 hPa) (Livesey et al., 2018). The MLS measurements have a coarser spatial resolution, and the sampling is not exactly coincident with SHOW. Therefore, some differences are expected between the measurements. However, both sensors sample nearly the same region in the vicinity of the subtropical jet. Therefore, the MLS measurements are used to check for consistency with the meteorological picture in comparison with the SHOW measurements.

The AURA-MLS measurements of water vapour and ozone are shown in Fig. 7a and b respectively. The corresponding PTLR plot is shown in Fig. 7c. For this comparison we use the 22:00 UTC time step of the ECMWF ERA5 reanalysis, since it is the closest available time step to the MLS measurements which occurred at close to 21:50 UTC.

The distributions of the two trace species have a spatial structure that matches the general shape of the structure observed in the PTLR plot and PV contours. As expected, the vertical distributions of the trace species are basically inverted, with water vapour decreasing with increasing altitude and vice versa for ozone. Most importantly, a filamentary structure is observed that extends from 36 to $42^{\circ} \mathrm{N}$ near $16 \mathrm{~km}$ and coincides with the presence of a double tropopause. Again, the feature matches a similar structure that is observed in the corresponding PTLR plot and PV contours at a lower altitude $(\sim 15 \mathrm{~km})$.

Taking the sharpest gradient in the PTLR to define the boundary between tropospheric and stratospheric air, we see that tropospheric air is primarily characterized with a PTLR $<12 \mathrm{~K} \mathrm{~km}^{-1}$ and stratospheric air is characterized with a PTLR $>12 \mathrm{~K} \mathrm{~km}^{-1}$. Therefore, as was the case with the SHOW measurements, the observed filamentary structure with a PTLR $<12 \mathrm{~K} \mathrm{~km}^{-1}$ is consistent with the intrusion of a low-static-stability air from the subtropical troposphere into the mid-latitude lower stratosphere. Mixing on the poleward side of the subtropical jet results in moistening and diminished ozone in the lowermost stratosphere.

The spatial structures recorded by SHOW (Fig. 6) and MLS (Fig. 7) during this event are strikingly similar and are consistent with spatial structures in the meteorological fields. A direct comparison shows that both instruments recorded similar amounts of water vapour in the vicinity of the subtropical jet. They both capture the moist filament near $16 \mathrm{~km}$ as well as the dry regions near $14 \mathrm{~km}$ in the lower-latitude portion of the measurement tracks. However, the coarser vertical resolution of MLS smears the vertical extent of the moist filament across a large vertical range of $\sim 2 \mathrm{~km}$.

Interestingly, the spatial structures observed in the MLS ozone and water vapour profiles are both shifted to a higher altitude relative to the PTLR and PV structures. Regardless, it is clear that the spatial variability observed in the MLS ozone and water vapour measurements, in light of the higher-
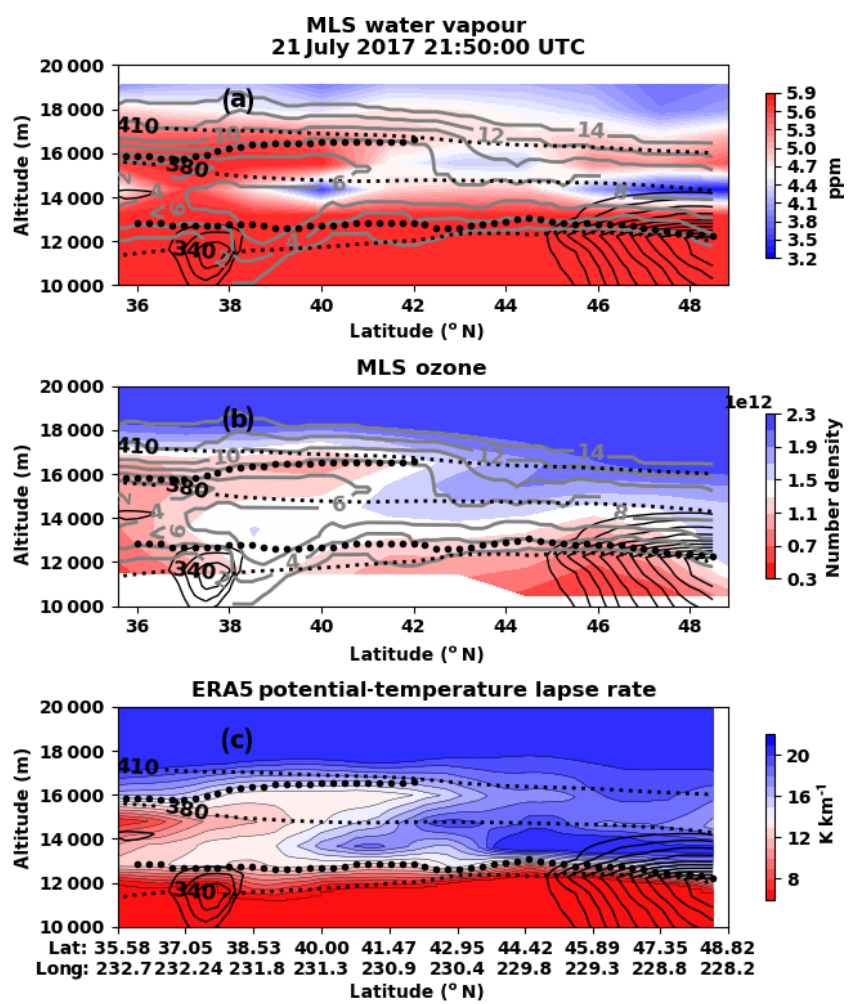

Figure 7. MLS-measured water vapour profile (a), ozone (b), and the potential-temperature lapse rate determined from the ERA5 reanalysis for the 22:00 UTC time step along the MLS measurement track (c).

resolution SHOW observations, is consistent with isentropic mixing on the poleward side of the subtropical jet in the presence of a double tropopause.

\section{Discussions and conclusions}

The SHOW measurements presented in this paper reveal fine spatial structures with vertical scales $<1 \mathrm{~km}$ in the twodimensional water vapour profile near the subtropical jet. The meteorological picture that was presented in Sect. 2 indicates that these structures are associated with isentropic transport and mixing due to the "stirring" of a Rossby wavebreaking event in the days leading up to the flight. The highvertical-resolution measurements of the two-dimensional water vapour distribution provide a detailed window into the mixing processes that is not completely resolved in the reanalysis dynamical fields or the AURA-MLS measurements.

The vertical resolution of the measurements determined from the full-width half maximum of the retrieval averaging kernel is $250 \mathrm{~m}$, and the precision on the measurements is $<0.3 \mathrm{ppm}$. The accuracy of the SHOW measurements and retrieval approach was examined in Langille et al. (2018) and was found to be $<0.5 \mathrm{ppm}$ for a wide range of water vapour variability and background aerosol. The approximate line-of- 
sight accuracy of the SHOW observations determined from the flight data is $<150 \mathrm{~m}$ in the $13-18 \mathrm{~km}$ region. Comparison with collocated radiosonde measurements obtained during an engineering flight on 17 July 2017 also showed excellent agreement (Langille et al., 2019). This provides a reasonable level of confidence that the variability observed in Fig. 6 is reflective of the true state of the atmosphere at the time of measurement.

However, we must also note that the SHOW-retrieved profile is sensitive to the upper and lower cut-off of the retrieval. In this paper, the upper boundary was chosen to be roughly $2 \mathrm{~km}$ below the aircraft altitude. Above this level, the sensitivity to water vapour is significantly reduced as the path between the aircraft and tangent point decreases. On the other hand, the lower boundary was chosen to be several kilometres below the lapse rate tropopause at the beginning of the measurements. Below this level, the optical depth becomes too large to accurately retrieve water vapour information (see Langille et al., 2018).

Ideally, this lower cut-off would be actively chosen to track changes in the altitude of the lapse rate tropopause and allow retrievals several kilometres below this altitude; however, the retrieval run was performed without a priori knowledge of the meteorological picture. An active determination is also under development that utilizes the sensitivity of the Jacobian to changes in the water vapour profile to determine the appropriate cut-off (Langille et al., 2018). In this paper, the lower boundary cut-off was fixed at $13.5 \mathrm{~km}$ using knowledge obtained from simulated retrievals in order to ensure that the retrieval was not influenced by this effect.

The objective of the comparisons with the reanalysis data, as well as AURA-MLS observations, is to identify the dynamical process that produced the measured water vapour structure. A number of factors can contribute to the differences and the offset displayed in the comparison. The reanalysis data have a vertical resolution of $1-3 \mathrm{~km}$ in the UTLS region. Therefore, the reanalysis data set has been used to confirm that the observed variability is consistent with the general meteorological picture and isentropic mixing associated with Rossby wave breaking near the subtropical jet. On the other hand, the MLS measurements provide a means to confirm consistency with the large-scale spatial variability; however, the measurements are not expected to have exact agreement, since the MLS measurements are made along a flight track that samples a slightly different region of the atmosphere. Also, the limb-viewing geometry from a satellite is different from the aircraft, and the AURA-MLS measurements have a lower vertical resolution $(1.3-3.2 \mathrm{~km}) \mathrm{com}$ pared to the SHOW measurements $(250 \mathrm{~m})$. The overall consistency supports the process identification despite the specific difference.

In conclusion, the high-spatial resolution measurements of a two-dimensional structure of the water vapour transport above and poleward of the subtropical jet provide unprecedented details of isentropic mixing across the tropopause break driven by Rossby wave breaking. The observed enhancement of water vapour in the lowermost stratosphere indicates that this type of transport is a significant process for the stratospheric water vapour budget. The fine structure of the water vapour in the mixing process supports the importance of the high-resolution water vapour measurement capability. These measurements also serve to demonstrate the capabilities of the SHOW instrument and further advance the technical readiness of the instrument for future satellite deployment.

Data availability. The ERA5 reanalysis product was downloaded from the Copernicus Climate Data Store: https://cds.climate. copernicus.eu/cdsapp\#!/dataset/reanalysis-era5-pressure-levels (last access: 1 October 2019). The AURA-MLS version 4.2 water vapour and ozone data utilized in this paper were downloaded from the GES-DISC link found at https://mls.jpl.nasa.gov/data/ (last access: 5 April 2019). SHOW data utilized in this paper are available upon request from the author.

Author contributions. JL and AB conceived this study and led the measurement campaign. JL led the interpretation of the measurements and writing of the paper, with significant contributions from LLP. BS is the originator of the instrumentation and contributed to the measurement campaign. DL and DZ made important contributions to the analysis. $\mathrm{DD}$ and $\mathrm{AB}$ are co-investigators of the project.

Competing interests. The authors declare that they have no conflict of interest.

Financial support. This research has been supported by the Canadian Space Agency through the Space Technology Development Program.

Review statement. This paper was edited by Farahnaz Khosrawi and reviewed by two anonymous referees.

\section{References}

Añel, J. A., Antuña, J. C., De La Torre, L., Castanheira, J. M., and Gimeno, L.: Climatological features of global multiple tropopause events, J. Geophys. Res.-Atmos., 113, D7, https://doi.org/10.1029/2007JD009697, 2008.

Banerjee, A., Chiodo, G., Previdi, M., Ponater, M., Conley, A. J., and Polvani, L. M.: Stratospheric water vapour: an important climate feedback, Clim. Dynam., 53, 1697-1710, https://doi.org/10.1007/s00382-019-04721-4, 2019.

Chen, P.: Isentropic cross-tropopause mass exchange in the extratropics, J. Geophys. Res., 100, 16661-16673, https://doi.org/10.1029/95jd01264, 1995. 
de Forster, P. M. F. and Shine, K. P.: Stratospheric water vapour changes as a possible contributor to observed stratospheric cooling, Geophys. Res. Lett., 26, 3309-3312, https://doi.org/10.1029/1999GL010487, 1999.

de Forster, P. M. F. and Shine, K. P.: Assessing the climate impact of trends in stratospheric water vapour, Geophys. Res. Lett., 29, 10-1-10-4, https://doi.org/10.1029/2001gl013909, 2002.

Dessler, A. E., Hintsa, E. J., Weinstock, E. M., Anderson, J. G., and Chan, K. R.: Mechanisms controlling water vapour in the lower stratosphere: "A tale of two stratospheres", J. Geophys. Res.Atmos., 100, 23167-23172, https://doi.org/10.1029/95JD02455, 1995.

Dessler, A. E., Schoeberl, M. R., Wang, T., Davis, S. M., and Rosenlof, K. H.: Stratospheric water vapour feedback, P. Natl. Acad. Sci. USA, 110, 18087-19091, https://doi.org/10.1073/pnas.1310344110, 2013.

Gettelman, A., Hegglin, M. I., Son, S. W., Kim, J., Fujiwara, M., Birner, T., Kremser, S., Rex, M., Añel, J. A., Akiyoshi, H., Austin, J., Bekki, S., Braesike, P., Brhl, C., Butchart, N., Chipperfield, M., Dameris, M., Dhomse, S., Garny, H., Hardiman, S. C., Jöckel, P., Kinnison, D. E., Lamarque, J. F., Mancini, E., Marchand, M., Michou, M., Morgenstern, O., Pawson, S., Pitari, G., Plummer, D., Pyle, J. A., Rozanov, E., Scinocca, J., Shepherd, T. G., Shibata, K., Smale, D., Teyssdre, H., and Tian, W.: Multimodel assessment of the upper troposphere and lower stratosphere: Tropics and global trends, J. Geophys. Res.-Atmos., 115, D3, https://doi.org/10.1029/2009JD013638, 2010.

Hintsa, E. J., Boering, K. A., Weinstock, E. M., Anderson, J. G., Gary, B. L., Pfister, L., Daube, B. C., Wofsy, S. C., Loewenstein, M., Podolske, J. R., Margitan, J. J., and Bui, T. P.: Troposphereto-stratosphere transport in the lowermost stratosphere from measurements of $\mathrm{H}_{2} \mathrm{O}, \mathrm{CO}_{2}, \mathrm{~N}_{2} \mathrm{O}$ and $\mathrm{O}_{3}$, Geophys. Res. Lett., 25, 2655-2658, https://doi.org/10.1029/98GL01797, 1998.

Holton, J. R., Haynes, P. H., McIntyre, M. E., Douglass, A. R., Rood, R. B., and Pfister, L.: Stratosphere-troposphere exchange, Rev. Geophys., 108, D12, https://doi.org/10.1029/95RG02097, 1995.

Homeyer, C. R., Bowman, K. P., Pan, L. L., Atlas, E. L., Gao, R. S., and Campos, T. L.: Dynamical and chemical characteristics of tropospheric intrusions observed during START08, J. Geophys. Res.-Atmos., 116, D6, https://doi.org/10.1029/2010JD015098, 2011.

Khosrawi, F., Lossow, S., Stiller, G. P., Rosenlof, K. H., Urban, J., Burrows, J. P., Damadeo, R. P., Eriksson, P., García-Comas, M., Gille, J. C., Kasai, Y., Kiefer, M., Nedoluha, G. E., Noël, S., Raspollini, P., Read, W. G., Rozanov, A., Sioris, C. E., Walker, K. A., and Weigel, K.: The SPARC water vapour assessment II: comparison of stratospheric and lower mesospheric water vapour time series observed from satellites, Atmos. Meas. Tech., 11, 4435-4463, https://doi.org/10.5194/amt-11-4435-2018, 2018.

Kley, D., Russel J. M., and Phillips, D.: SPARC assessment of upper tropospheric and stratospheric water vapour, WCRP 113, World Meteorol. Organ., WMO/TD - No. 143, SPARC report no. 2, Geneva, Switz, 2000.

Kunz, A., Konopka, P., Müller, R., and Pan, L. L.: Dynamical tropopause based on isentropic potential vorticity gradients, J. Geophys. Res., 116, D01110, https://doi.org/10.1029/2010JD014343, 2011a.
Kunz, A., Pan, L. L., Konopka, P., Kinnison, D. E., and Tilmes, S.: Chemical and dynamical discontinuity at the extratropical tropopause based on START08 and WACCM analyses, J. Geophys. Res.-Atmos., 116, D24, https://doi.org/10.1029/2011JD016686, 2011 b.

Langille, J. A., Solheim, B., Bourassa, A., Degenstein, D., Brown, S., and Shepherd, G. G.: Measurement of water vapour using an imaging field-widened spatial heterodyne spectrometer, Appl. Opt., 26, 4297-4308, https://doi.org/10.1364/AO.56.004297, 2017.

Langille, J. A., Letros, D., Zawada, D., Bourassa, A., Degenstein, D., and Solheim, B.: Spatial Heterodyne Observations of Water (SHOW) vapour in the upper troposphere and lower stratosphere from a high altitude aircraft: Modelling and sensitivity analysis, J. Quant. Spectrosc. Ra., 209, 137-149, https://doi.org/10.1016/j.jqsrt.2018.01.026, 2018.

Langille, J., Letros, D., Bourassa, A., Solheim, B., Degenstein, D., Dupont, F., Zawada, D., and Lloyd, N. D.: Spatial heterodyne observations of water (SHOW) from a high-altitude airplane: characterization, performance, and first results, Atmos. Meas. Tech., 12, 431-455, https://doi.org/10.5194/amt-12-431-2019, 2019.

Livesey, N. J., Read, W. G., Wagner, P. A., Froidevaux, L., Lambert, A., Manney, G. L., Valle, L. F. M., Pumphrey, H. C., Santee, M. L., Schwartz, M. J., Wang, S., Fuller, R. A., Jarnot, R. F., Knosp, B. W., Martinez, E., and Lay, R. R.: Earth Observing System (EOS) Aura Microwave Limb Sounder (MLS) version $4.2 \times$ level 2 data quality and description document, 2018.

Nedoluha, G. E., Kiefer, M., Lossow, S., Gomez, R. M., Kämpfer, N., Lainer, M., Forkman, P., Christensen, O. M., Oh, J. J., Hartogh, P., Anderson, J., Bramstedt, K., Dinelli, B. M., GarciaComas, M., Hervig, M., Murtagh, D., Raspollini, P., Read, W. G., Rosenlof, K., Stiller, G. P., and Walker, K. A.: The SPARC water vapor assessment II: intercomparison of satellite and ground-based microwave measurements, Atmos. Chem. Phys., 17, 14543-14558, https://doi.org/10.5194/acp-17-145432017, 2017.

Pan, L., Solomon, S., Randel, W., Lamarque, J. F., Hess, P., Gille, J., Chiou, E. W., and McCormick, M. P.: Hemispheric asymmetries and seasonal variations of the lowermost stratospheric water vapour and ozone derived from SAGE II data, J. Geophys. Res.Atmos., 102, 28177-28184, https://doi.org/10.1029/97jd02778, 1997.

Pan, L. L., Randel, W. J., Gille, J. C., Hall, W. D., Nardi, B., Massie, S., Yudin, V., Khosravi, R., Konopka, P., and Tarasick, D.: Tropospheric intrusions associated with the secondary tropopause, J. Geophys. Res., 114, D10302, https://doi.org/10.1029/2008JD011374, 2009.

Randel, W. J., Seidel, D. J., and Pan, L. L.: Observational characteristics of double tropopauses, J. Geophys. Res.-Atmos., 112, D7, https://doi.org/10.1029/2006JD007904, 2007.

Ray, E. A., Moore, F. L., Elkins, J. W., Dutton, G. S., Fahey, D. W., Vömel, H., Oltmans, S. J., and Rosenlof, K. H.: Transport into the Northern Hemisphere lowermost stratosphere revealed by in situ tracer measurements, J. Geophys. Res.-Atmos., 104, 2656526580, https://doi.org/10.1029/1999JD900323, 1999.

Riese, M., Ploeger, F., Rap, A., Vogel, B., Konopka, P., Dameris, M., and Forster, P.: Impact of uncertainties in atmospheric mixing on simulated UTLS composition and re- 
lated radiative effects, J. Geophys. Res.-Atmos., 117, D16, https://doi.org/10.1029/2012JD017751, 2012.

Schwartz, M. J., Manney, G. L., Hegglin, M. I., Livesey, N. J., Santee, M. L., and Daffer, W. H.: Climatology and variability of trace gases in extratropical double-tropopause regions from MLS, HIRDLS, and ACE-FTS measurements, J. Geophys. Res., 120, 843-867, https://doi.org/10.1002/2014JD021964, 2015.

Scott, R. K. and Cammas, J. P.: Wave breaking and mixing at the subtropical tropopause, J. Atmos. Sci., $\quad 59, \quad 2347-2361, \quad$ https://doi.org/10.1175/15200469(2002)059<2347:WBAMAT>2.0.CO;2, 2002.

Solomon, S., Rosenlof, K. H., Portmann, R. W., Daniel, J. S., Davis, S. M., Sanford, T. J., and Plattner, G. K.: Contributions of stratospheric water vapour to decadal changes in the rate of global warming, Science, 327, 1219-1223, https://doi.org/10.1126/science.1182488, 2010.
Ungermann, J., Pan, L. L., Kalicinsky, C., Olschewski, F., Knieling, P., Blank, J., Weigel, K., Guggenmoser, T., Stroh, F., Hoffmann, L., and Riese, M.: Filamentary structure in chemical tracer distributions near the subtropical jet following a wave breaking event, Atmos. Chem. Phys., 13, 10517-10534, https://doi.org/10.5194/acp-13-10517-2013, 2013.

WMO: Meteorology: A three dimensional science, WMO Bull., 6, 134-138, 1957.

WMO: International Meteorological Vocabulary, WMO Technical Publication No. 182, WMO, Geneva, Switzerland, 636-637, 1992. 